\title{
A PERCEPÇÃO DE SURDOS COMO SUBSÍDIO AO PROJETO: UM ESTUDO COM O USO DE MAQUETE FÍSICA
}

\author{
MEDEIROS, Ana Thereza Faria de (1); \\ ELALI, Gleice Azambuja (2) \\ (1) PPGAU/UFRN, Mestre \\ e-mail: anatherezafaria@hotmail.com \\ (2) PPGAU/UFRN, Dra. \\ e-mail:gleiceae@gmail.com
}

\begin{abstract}
RESUMO
Esse artigo apresenta uma experiência para facilitação da participação de surdos no projeto de laytout de livings em ambiente residencial. Apoiado nos conceitos de Projeto Participativo e DeafSpace, a atividade utilizou o modelo físico tridimensional como ferramenta para facilitar a comunicação entre o projetista/arquiteto e pessoas surdas. Participaram 12 surdos adultos, que realizaram experiencias de simulação por meio da manipulação de maquete, acompanhada por entrevistas e observações. Os resultados indicam a eficácia da metodologia utilizada, e apontam elementos essenciais para o projeto nesse campo.
\end{abstract}

Palavras chave: projeto participativo; pessoas surdas; ambiente residencial; maquete física tridimensional.

\begin{abstract}
This article presents an experience to facilitate the participation of deaf people in the design of living room layouts. Based on the concepts of Participative Project and DeafSpace, the activity utilized the three-dimensional physical model as a tool to facilitate communication between the designer / architect and deaf people. Twelve deaf adults participated in the study, who performed simulation experiments through model manipulation, followed by interviews and observations. The results indicate the effectiveness of the methodology used, and point out essential elements for the project in this field.
\end{abstract}

Keywords: participative design; Deaf People; housing environment; three-dimensional physical model.

\section{INTRODUÇÃO}

De acordo com o Censo de 2010 do Instituto Brasileiro de Geografia e Estatística (IBGE, 2012), no Brasil mais de 45 milhões de pessoas têm alguma deficiência, havendo mais de 2 milhões de deficientes auditivos. Ilustrando essa situação, no estado do Rio Grande do Norte, só na cidade de Natal há mais de 35.000 pessoas com algum tipo/grau de deficiência auditiva, um terço das quais incluídas na categoria de grande dificuldade ou perda total da audição, fato que, por si, justifica a realização da pesquisa pretendida.

As pessoas com deficiência auditiva necessitam de um conjunto de referências que facilite sua acessibilidade e mobilidade, sendo importante a realização de pesquisas sobre suas 


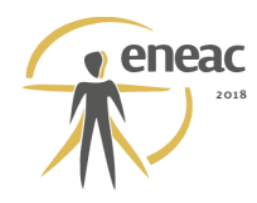

principais vias de percepção, comunicação e comportamento. No campo da arquitetura, grande parte da dificuldade da participação de pessoas com deficiência auditiva no processo projetual está relacionada à comunicação projetista-cliente. Partindo desse entendimento, a investigação mais ampla (MEDEIROS, 2018) tomou como questão-problema: "Como possibilitar que deficientes auditivos participem do processo projetual e interajam com 0 projetista?"

Para alicerçar essa discussão, a atividade empírica foi realizada em ambiente residencial, entendendo-se que a familiaridade com a habitação (como ambiente cotidiano) facilitaria o entendimento das questões de funcionalidade pelas as pessoas surdas. Além disso, no projeto residencial é essencial que o profissional estude os hábitos dos usuários, suas atividades, movimentos, equipamentos e mobiliário, de modo que a investigação apresentaria grande aplicabilidade prática. Como recorte foi definida a área de living (estar/jantar/cozinha), por se tratar de um ambiente de uso comum e grande permanência e, portanto, menos influenciável por características individuais (como seria, por exemplo, o dormitório). Nesse contexto, o objetivo geral do projeto de pesquisa foi investigar a utilização do modelo físico tridimensional como ferramenta de comunicação entre projetistas e usuários surdos, possibilitando a captação das necessidades destes últimos dentro de uma perspectiva de projeto participativo.

Esse artigo visa apresentar os principais resultados da experiência empírica, que envolveu 12 participantes adultos. Metodologicamente a experiência envolveu: (i) Confecção de maquete manipulável a ser utilizada pelos PSs; (ii) Confecção de mobiliário básico em escala adequada à maquete (utilizada para identificação de organizações espaciais); (iii) Realização de sessões de trabalho com maquetes envolvendo PSs e a pesquisadora, nas quais as PSs eram estimuladas a manipular a maquete para adequar o ambiente às suas necessidades, e contaram com o auxílio de intérprete para esclarecimento das mudanças realizadas.

\section{ALICERCES DA EXPERIÊNCIA}

A formulação da experiência apoiou-se na constatação da importância do processo comunicativo para a elaboração do projeto arquitetônico, e nas indicações do DeafSpace, delineados a seguir.

A comunicação é essencial para a criação e tradução do projeto arquitetônico. Quando um dos interlocutores do processo comunicativo é uma pessoa surda, as dificuldades inerentes à decodificação das mensagens entre as partes tornam-se consideravelmente maiores (FARIAS; SANDERSON; PORTO, 2013). Isso não diminui a necessidade dos surdos conseguirem interagir com em qualquer tipo de ambiente, nem a importância de viverem em sociedade. De fato, essas pessoas costumam utilizar uma linguagem própria, a linguagem de sinais, no Brasil intitulada Língua Brasileira de Sinais (LIBRAS), que é um idioma visual, com suas próprias regras e sinais pré-estabelecidos, que conduzem a comunicação entre aqueles que o dominam.

No campo da arquitetura a comunicação é um importante instrumento de intervenção no espaço, atuando em diversos momentos do processo de projeto. Ao iniciar um projeto, o arquiteto precisa encontrar uma maneira de exteriorizar suas ideias, transpondo-as para o papel de modo a poder visualizá-las e consolidá-las. Nesta etapa, diagramas, esboços, desenhos e anotações são consideradas formas de concepção do projeto e são uma forma de representar, externamente, o pensamento inicial do projetista. Essas representações externas são utilizadas, não apenas como auxiliares do processo criativo, mas também como facilitadores de tarefas de projeto, como, por exemplo, a verificação do atendimento a condicionantes, a compreensão do problema e a própria busca de soluções através da geração e registro de alternativas para posterior avaliação, confrontação e refinamento (BORGES, NAVEIRO, 2001). Os meios utilizados, como desenho e maquete, correspondem 


\section{$\mathfrak{\pi}^{\text {eneac }}$}

à materialização dessas ideias, num momento bastante anterior à construção efetiva da edificação, sendo imprescindível o diálogo entre os meios de representação, quer textuais, quer gráficos ou tridimensionais.

Sob esse ponto de vista, a equipe de especialistas (entre eles o arquiteto) tem a responsabilidade de desenvolver um processo de avaliação que transforme a experiência, o conhecimento e os valores do usuário em ambientes com maior qualidade (IMAI, 2009).

Obviamente a participação efetiva impõe grande carga de solicitações/demandas/ responsabilidades aos envolvidos (leigos e técnicos), o que, se por um lado dificulta o processo, por outro exige que a comunidade se organize e se comprometa com o resultado, o que pode ser útil em outras oportunidades. Além disso, quando o usuário sente que contribuiu com o processo de planejamento e execução da intervenção, sua satisfação com o resultado obtido é maior, e ele tende a se identificar mais com o mesmo (VELOSO, ELALI, 2014, p.4)

De fato, a participação dos usuários finais no processo de projeto promove inúmeros benefícios a todos os participantes. Em larga escala, a participação social resulta em ações projetuais mais eficazes e melhor gestão dos recursos destinados ao projeto (SANOFF, 2007 e 2008), possibilidade que se torna ainda mais evidente em se tratando da melhoria das condições de vida de pessoas com deficiência (BINS ELY, 2004; DISCHINGER et al, 2012).

Nesse campo, o uso de modelos tridimensionais mostra-se especialmente adequado, pois trata-se de um instrumento de representação facilmente compreensível e que garante maior percepção de espacialidade, além de atuar como recurso lúdico, acessível a praticamente todas as pessoas. Nesse campo, a literatura nesse campo (IMAI, 2009; IMAl et al, 2015; GANJU, GUPTA, KHOSLA, 2012; ROZESTRATEN, 2017) indica que a maquete física proporciona o contato direto do cliente/leigo com a ideia do projetista, sendo fundamental salientar que, embora as pessoas leigas não possuam conhecimentos técnicos que possibilitem uma leitura eficaz de um modelo bidimensional, seu contato cotidiano com um ambiente os torna aptos a opinarem e atuarem sobre ele. Em área residencial, por exemplo, a população desenvolve grande "(...) conhecimento dos espaços da casa, desenvolvidos a partir da vivência de cada um" (ZALITE, 2016, p. 44).

Para facilitar a participação dos usuários durante todo o processo de projeto, os instrumentos para representação do projeto devem incorporar uma linguagem comunicacional didática e acessível que permitam a captura de informações referentes às percepções espaciais da população leiga. Enquanto modelo em escala reduzida de um edifício, a maquete pode ser compreendida como uma extensão do croqui, acrescida da terceira dimensão, e assume um papel fundamental na compreensão da linguagem gráfica e técnica do projeto, permitindo melhor entendimento da edificação, inclusive para o projetista. Ela auxilia a previsão de erros e problemas dificilmente detectáveis na representação bidimensional e auxilia na compreensão de etapas posteriores de execução, facilitando a troca de ideias entre projetistas, outros profissionais e usuários, sobretudo aqueles com pouca experiência em leitura de desenhos técnicos, esclarecendo questões relacionadas à espacialidade, às combinações estéticas, aos aspectos construtivos e estruturais e às interações entre interior e exterior.

Ao manipular a maquete física o leigo pode realizar modificações, o que facilita o entendimento da proposta e melhora a comunicação entre as partes, entendimento que se mantém, apesar dos atuais avanços tecnológicos das maquetes digitais/virtuais, que precisam de um alto grau de conhecimento técnico para a sua construção, o que impossibilita a intervenção direta de leigos em seu desenvolvimento.

Nesse contexto, o DeafSpace se caracteriza como uma tentativa de criar uma "sabedoria coletiva" sobre a construção de espaços adequados às sensibilidades cognitivas, 


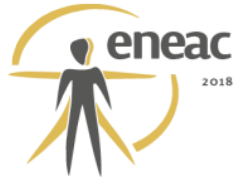

linguísticas e culturais das pessoas surdas, a serem utilizadas como orientação ao projeto. Seu desenvolvimento começou em 2005, em um workshop realizado na Universidade de Gallauted, voltado para estabelecer princípios de projeto para a construção de um novo centro de comunicação de linguagem em Sorenson, Campus da Gallaudet. O grupo buscava a definição de um lugar que revelasse a conexão das pessoas surdas entre si, envolvendo: senso de comunidade, desejo de abertura e luz, sentimento de bem-estar e consciência de natureza, priorização da visão e do tato como elementos primários de consciência espacial e orientação (BAUMAN, 2014).

Em termo arquitetônicos, o DeafSpace não visa assegurar soluções universais, ao contrário, busca promover situações sócio espaciais particulares que possam conectar de modo sensível e significativo os indivíduos uns aos outros e àquilo que está ao seu redor (TYSIMBAL, 2010), ou seja, proporcionar ambientes amigáveis para as pessoas com deficiência auditiva. As diretrizes projetuais traçadas estão subdivididas em: alcance sensorial; espaço e proximidade; mobilidade; luz e cor; acústica e interferências eletromagnéticas (HURLEY, 2016)

\section{MÉTODO}

A pesquisa compreendeu simulação com a maquete, questionário e entrevista (nãoestruturada) posterior à montagem, buscando coletar expectativas, sentimentos, e detalhes da interação do participante com a maquete e seus elementos; permitindo, ainda, a interpretação de gestos e a realização de perguntas não programadas, sempre que necessário.

Durante a atividade a atuação de intérpretes foi fundamental mas, ao invés de um intérprete oficial, optou-se por membros da família dos surdos participantes devido à aproximação pessoal e cotidiana entre ambos, o que contribuiu tanto para questões de confiabilidade entre ele e a pessoa surda como para questões de interpretação dos elementos relativos à tomada de decisão.

A elaboração da maquete física básica teve como base os trabalhos de Imai (2009) e Zalite (2016). A maquete foi construída na escala de 1:10 para facilitar o entendimento e a manipulação de objetos em seu interior. Tal escala, além de permitir a manipulação pelo usuário, possibilitou que pesquisadora transportasse o material sem muita dificuldade. Além disso, a eventual conversão de medidas da escala de 1:10 para a escala real é mais simples do que seria a conversão de outras escalas (1:5 ou 1:20, por exemplo).

Para fabricação das paredes, foram utilizadas folhas de poliestireno expandido (EPS) de $9 \mathrm{~mm}$ de espessura com revestimento em ambos os lados com folha de acetato na cor branca. A escolha do material levou em consideração a facilidade de manuseio e transporte (uso do EPS), assim como a resistência às múltiplas utilizações (uso do acetato). As paredes foram produzidas em 4 dimensões distintas: três módulos de $1 \mathrm{~m}$, extensíveis até $1,90 \mathrm{~m}$; quatro módulos de $2 \mathrm{~m}$ extensíveis até $3,90 \mathrm{~m}$; três módulos de $3 \mathrm{~m}$, extensíveis até $5,90 \mathrm{~m}$; quatro módulos de $4 \mathrm{~m}$, extensíveis até $7,90 \mathrm{~m}$. As dimensões das extensões são facilitadas com a presença de uma régua-guia na parte superior da parede, possibilitando a visualização imediata do dimensionamento final da parede. Dessa forma, os módulos fornecem uma grande variedade de organização e disposição dos ambientes solicitado. As esquadrias foram elaboradas de modo a se sobrepor às paredes por meio de encaixe. Dessa forma, os participantes poderiam manipula-las de forma livre, com várias opções de implantação.

Foram desenvolvidas 6 possibilidades diferentes de portas (entre 0,80m e 1,0m), além da existência ou não de portais laterais em vidro, num total de quatorze opções manipuláveis. 


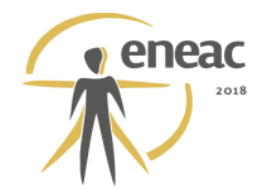

Em relação às janelas a variedade foi ainda maior, pois consideramos duas divisões: janelas com peitoril tradicional $(1 \mathrm{~m})$ e com peitoril elevado (acima de $1,10 \mathrm{~m}$ ), que poderiam ser instaladas na cozinha, possibilitando a instalação de armários acima dela. Suas dimensões variavam de 1,20 metros a 2,00 metros de largura, com opções de divisões de duas a quatro folhas de vidro. No total, foram confeccionadas dezoito janelas.

O mobiliário foi reproduzido a partir do dimensionamento antropométrico básico proposto por Pronk (2003) e Neufert (2013), bem como no uso de medidas fornecidas por fabricantes em sites de vendas de eletrodomésticos. Suas características foram delimitadas de modo a se aproximarem ao real, facilitando a compreensão e identificação das peças. $O$ material contém peças específicas para sala de estar, sala de jantar e cozinha, o que envolve mesas e cadeiras de refeições, poltronas, sofás, mesinhas laterais, fogões, geladeiras, bancadas de trabalho e outros.

Figura 1. Maquete: régua-guia para extensão da parede

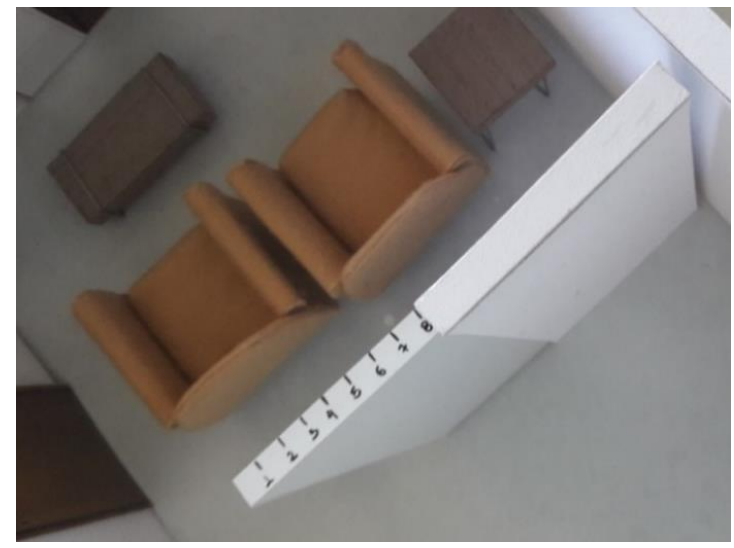

Fonte: Medeiros (2018)

Figura 2. Maquete: encaixe das esquadrias sobre as paredes

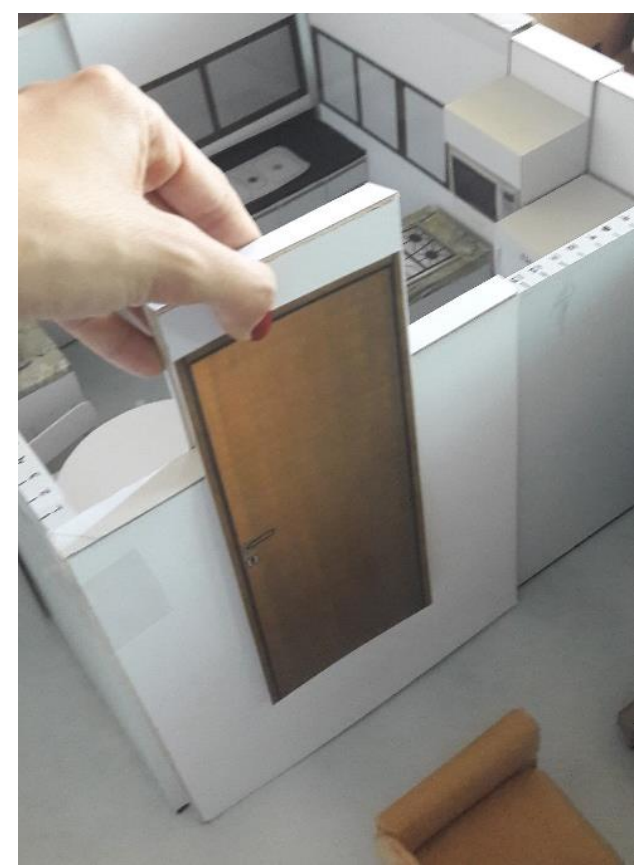

Fonte: Medeiros (2018) 


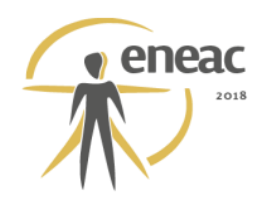

A experiência seguiu o seguinte procedimento:

(i) Descrição, para cada participante, dos objetivos e da importância de sua contribuição, notadamente no que se referiu a questões de compreensão do modelo e das possibilidades de contribuir com as definições de um projeto de habitação.

(ii) Montagem de um modelo pré-desenvolvido pela pesquisadora simulando uma proposta inadequada à utilização por uma pessoa surda (Figura 3). Após a montagem era questionado à pessoa surda se ela identificava algum problema em relação à organização dos ambientes e do mobiliário. Em seguida eram mostrados, item por item, os pontos que, com base nos estudos teóricos realizados durante a pesquisa, poderiam trazer problemas ao uso.

(iii) Montagem, seguindo uma planta pré-estabelecida, de um modelo contendo características favoráveis à utilização do ambiente por uma pessoa surda (Figura 4). Essa planta foi desenvolvida a partir dos princípios arquitetônicos do DeafSpace. Por ser um estudo comparativo com o anterior foi mantida uma aproximação da área total nos dois casos, com cerca de $41 \mathrm{~m}^{2}$. Apesar de se reconhecer a importância de utilização de cores de pouco contraste nos ambientes, dada a grande quantidade de aspectos investigados, nesta pesquisa optamos por não adentrar nessa questão.

(iv) Após mostrados os dois modelos supracitados, a proposta desenvolvida na etapa 01 era refeita para que $\mathrm{a}(0)$ entrevistada(o) o manipulasse fazendo as alterações que considerasse necessárias. Neste ponto eram feitos questionamentos acerca da ideia inicialmente desenvolvida e das alterações que surgissem.

Foram feitas doze simulações com diferentes usuários entre outubro e dezembro de 2017, sendo 04 participantes do sexo feminino e 08 do masculino, cujas idades variaram entre 20 e 45 anos. Cada simulação durou em média quarenta e cinco minutos, foi registrada por imagens, vídeo, áudio e anotações escritas.

A investigação atendeu às exigências da Ética na Pesquisa, tendo sido autorizada pelo Comitê de Ética do Hospital Universitário Onofre Lopes, da UFRN, parecer nํㅜ 2.052.74. Os participantes foram devidamente instruídos e assinaram o Termo de Consentimento Livre e Esclarecido (TCLE). 
Figura 3. Configuração espacial considerada inadequada para pessoas surdas

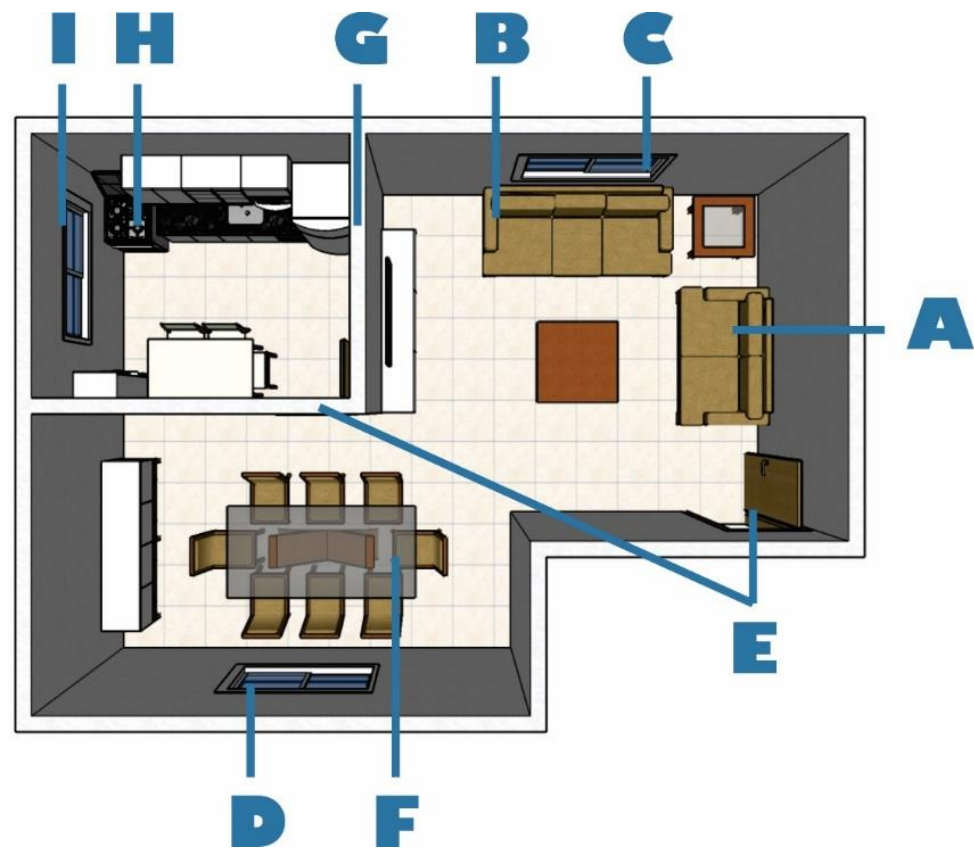

Fonte: Medeiros (2018)

LEGENDA:

(A) O posicionamento dos sofás, um ao lado do outro, em formato de "L" dificulta a comunicação entre os surdos, pois eles precisam fazer o movimento de tronco/cabeça.

(B) De modo semelhante, percebemos que a pessoa que estiver sentada no sofá de 3 lugares terá que se virar para assistir à tevê, ficando em uma posição desconfortável.

(C) O posicionamento da janela, atrás do sofá e, consequentemente, da pessoa que o estiver ocupando, provoca uma sensação de ofuscamento, dificultando a leitura gestual e comunicação, indo contra o princípio de luz e cor proposto por Bauman (2014).

(D) Os dimensionamentos das janelas dos três ambientes foram reduzidos de modo a proporcionar o mínimo de iluminação natural exigido pela legislação municipal, criando a necessidade de uma possível utilização de luz artificial nestes ambientes para se obter uma boa iluminação.

(E) Foi proposta uma porta de folha cega para a entrada da edificação, pela sala de estar. Esta porta impede a visualização/percepção da presença de outras pessoas no exterior da casa. O mesmo estilo de porta foi colocado no acesso à cozinha.

(F) A mesa escolhida para a sala de jantar foi uma retangular, com 6 cadeiras, dispostas em duas fileiras de 3, estando uma ao lado da outra. Utilizando um conceito semelhante ao da disposição dos sofás, as pessoas surdas necessitam virar-se para poder haver a comunicação em LIBRAS, gerando posições de desconforto.

(G) A organização dos ambientes, compartimentados, dificulta a visualização dos espaços da casa, diminuindo a percepção dos acontecimentos dos outros cômodos pelas pessoas surdas.

(H) O posicionamento do fogão e da pia, no lado oposto à entrada da cozinha, impede a visualização, por quem os estiver utilizando, de quem entra no ambiente. Essa disposição também impede que a pessoa que estiver cozinhando e/ou lavando a louça, por exemplo, mantenha contato com outras pessoas que estejam na cozinha.

(I) O posicionamento da janela da cozinha, na lateral do ambiente, dificulta a visualização durante as atividades domésticas, como cozinhar, lavar a louça ou fazer as refeições. 
Figura 4. Configuração espacial considerada adequada para pessoas surdas

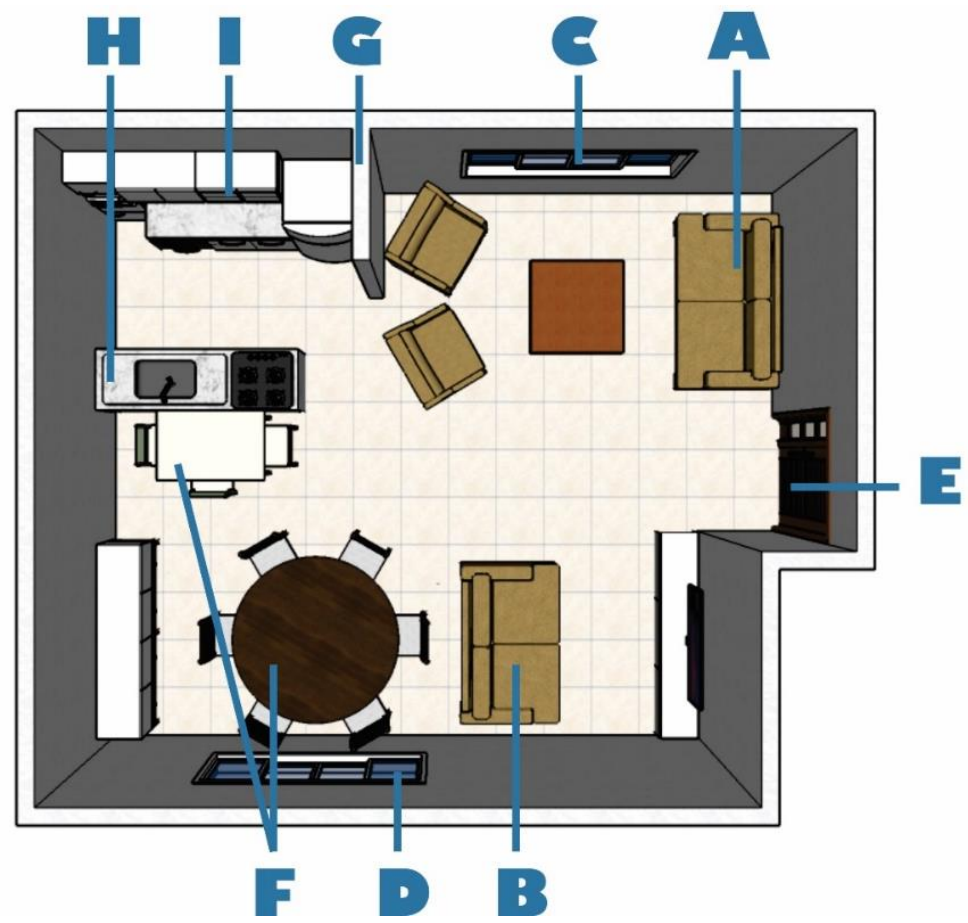

Fonte: Medeiros (2018)

\section{LEGENDA}

(A) Os sofás, antes posicionados um ao lado do outro, foram reorganizados de modo a ficarem de frente um para o outro, facilitando a comunicação. Um dos sofás foi substituído por duas poltronas de modo a facilitar uma possível mobilidade entre o grupo.

(B) Foi proposto um outro ambiente, separado, para acomodar a tevê, de modo que o sofá ficasse de frente para ela, melhorando a sua visualização.

(C) A janela, antes posicionada atrás do sofá, agora está na lateral dos mesmos, melhorando a iluminação nas pessoas e evitando o ofuscamento de antes.

(D) Os dimensionamentos das janelas dos três ambientes foram reduzidos de modo a proporcionar o mínimo de iluminação natural exigido pela legislação municipal, criando a necessidade de uma possível utilização de luz artificial nestes ambientes para se obter uma boa iluminação.

(E) Para a entrada da edificação optamos por uma porta com visor lateral em vidro, que permite a visualização e percepção de pessoas do lado externo da casa. Essa opção deve ser utilizada em conjunto com a campainha luminosa, que também faz notar a presença de pessoas do outro lado da porta por meio de um sinal luminoso, que deve ser instalado em diversos cômodos da casa.

(F) A mesa escolhida para a sala de jantar foi uma circular, também com 6 cadeiras, de modo a permitir uma perfeita visualização de todas as pessoas que estiverem sentadas à mesa, independentemente do local onde estiverem, garantindo, assim, as características de espaço e proximidade (BAUMAN, 2014). De modo semelhante, a mesa das refeições diárias, junto à bancada que possui a pia e o cooktop, também tem formato quadrado, que permite a disposição das cadeiras frente a frente.

(G) A organização dos ambientes mais ampla e sem paredes divisórias, permite que o/a surdo/a perceba o que acontece nos outros ambientes, além de facilitar a comunicação com pessoas em outros cômodos garantindo o alcance sensorial (BAUMAN, 2014)

(H) O posicionamento do fogão e da pia, no lado oposto à entrada da cozinha, impede a visualização, por quem os estiver utilizando, de quem entra no ambiente. Essa disposição também impede que a pessoa que estiver cozinhando ou lavando a louça, por exemplo, mantenha contato com outras pessoas que estejam na cozinha. 


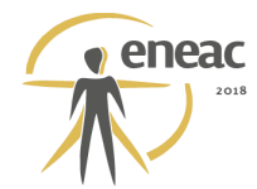

\section{PRINCIPAIS RESULTADOS}

A pesquisa envolveu muitos elementos e uma grande quantidade de resultados, quanto a tipo de abertura escolhidas, características e posição dos móveis, conforme exemplifica a Figura 5.

Figura 5. Proposta desenvolvida por um dos participantes
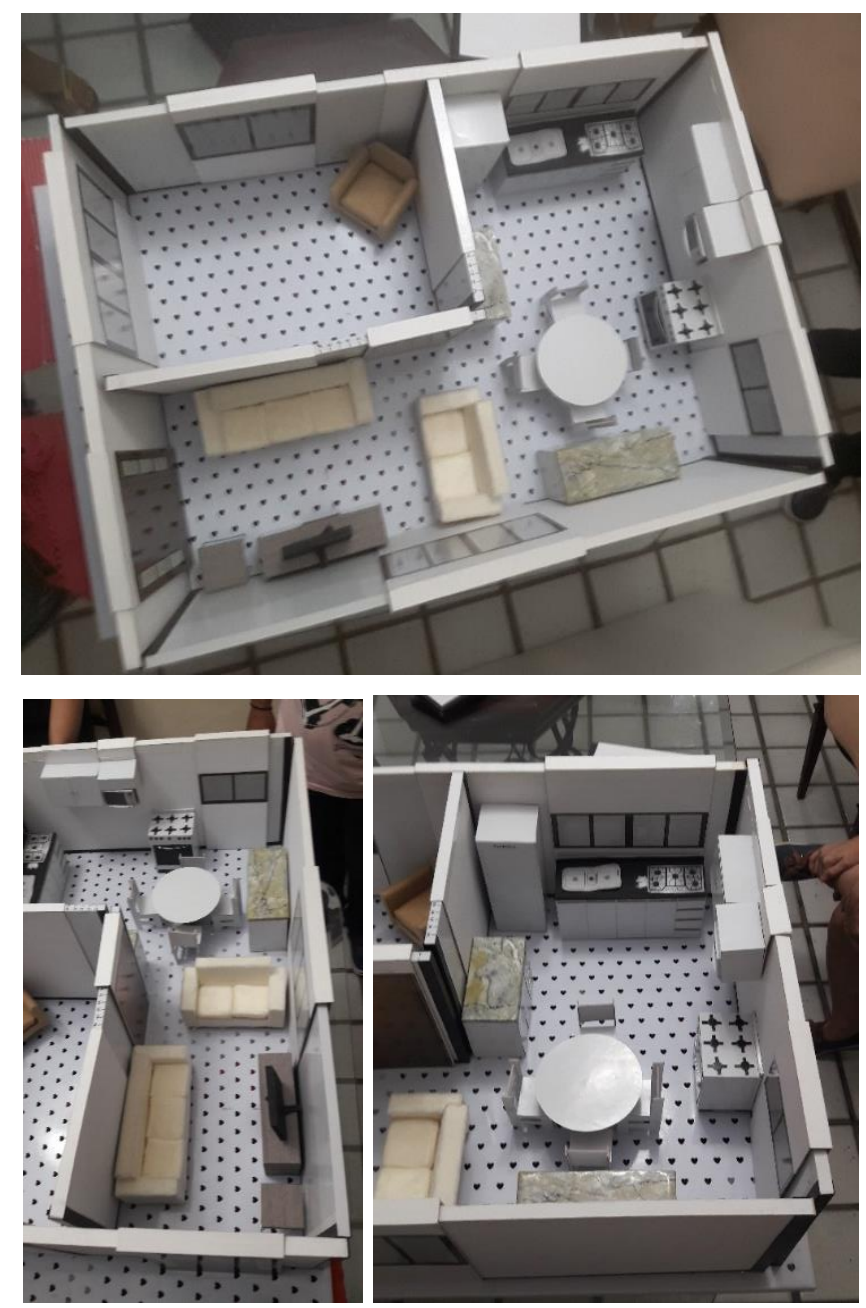

Fonte: Medeiros (2018)

Apesar da grande riqueza de detalhes a serem explorados, os principais achados identificados na investigação foram de cunho genérico, tais como:

- durante a manipulação da maquete, a maioria dos participantes não se limitou à organização espacial dos três ambientes solicitados, se estendendo a outros cômodos da casa, como os quartos e até banheiro e garagem, o que demonstrou que conseguiram compreender e organizar melhor as partes (sala de estar, jantar e cozinha) pelo todo (demais ambientes).

- vários participantes demonstraram grande apego ao ambiente em que moram, que tentaram reproduzir as suas casas; assim, mesmo percebendo pontos negativos no modelo desenvolvido, eles não fizeram muitas alterações na proposta. 


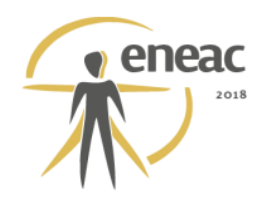

- alguns participantes desenvolveram uma organização espacial diferente da sua própria casa, o que mostra que as escolhas e disposição dos ambientes partiu da sua própria necessidade, sem a tentativa de reprodução de um ambiente que já lhe é muito familiar.

- preocupação com aspectos térmicos do local, muito comentados durante as experiências, envolvendo desde o cuidado com o posicionamento do fogão na cozinha à localização e dimensionamento das janelas nos ambientes de uma forma geral.

- grande preferência pela colocação do mobiliário próximo às paredes, talvez como modo de ampliar o controle sobre o espaço.

- preferência por portas com visores, facilitando o contato interior/exterior.

- a segurança foi uma questão não considerada incialmente, mas que aflorou na investigação, uma vez que alguns não inseriram janelas na cozinha e na sala informando que estas seriam facilmente quebradas por pessoas com más intenções.

- a integração do ambiente da cozinha à sala de estar e jantar, sem a presença da parede divisória, foi apontada como algo negativo por 02 participantes, que argumentaram não se sentirem à vontade com a exposição das ações desenvolvidas na cozinha - refeições, lavagem de louça, cocção, etc.; para eles a parede divisória transmite a ideia de privacidade, importante neste ambiente.

- posicionamento frequente da pia fora da cozinha, em um ambiente externo à casa, atitude associada às características culturais da região.

Além disso, outro importante achado relaciona-se ao fato de, em várias situações, os participantes terem preferido modos de organização do mobiliário que vão contra às condições de espaço e proximidade defendidas pelo Deaf Space, segundo o qual a pessoa surda necessitaria de um amplo campo de visão para se comunicar em língua de sinais, de modo que os interlocutores se visualizem continuamente. A partir dessa indicação, os participantes abriram a possibilidade de adaptarem-se a ambientes cujas soluções são menos adequadas às pessoas surdas, o que indica um caminho para novas investigações nesse campo, talvez valorizando diferenças culturais vivenciadas por diferentes subgrupos de pessoas surdas.

\section{CONSIDERAÇÕES FINAIS}

Considerando a dificuldade de comunicação das pessoas surdas em se tratando de expressar as suas necessidades e compreender a mensagem verbal de outras pessoas, a pesquisa realizada voltou-se para um modo de possibilitar a integração de deficientes auditivos a um processo projetual em arquitetura, interagindo com o profissional projetista durante o processo de projeto, no caso, para definição de um living residencial. Para tanto, a maquete física tridimensional foi utilizada como canal facilitador da comunicação.

Comprovou-se, assim, a importância da manipulação da maquete física tanto para o usuário como para o projetista, permitindo uma aproximação com o mundo real, de modo simples e sem a necessidade de conhecimento prévio de leitura de elementos de desenho técnico dimensional (plantas e cortes). Associados à maquete, a entrevista e questionário ajudaram à compreensão das escolhas dos participantes, em algumas situações dispensando até o uso do intérprete como mediador comunicativo (como no caso da escolha da porta com visor lateral). Portanto, a utilização da maquete se mostrou eficaz do posto de vista de compreensão da organização dos espaços, facilitando a identificação das preferências dos 


\section{(x) $^{\text {maxe }}$}

participantes, algumas das quais não seriam apontadas ou declaradas em questionários, pois dependem da percepção e capacidade de pensar em um plano abstrato.

\section{REFERÊNCIAS}

BAUMAN, H. DeafSpace: an architecture towards a more livable and sustainable world. In: BAUMAN, H.; MURRAY, J. J. (Ed.). Deaf Gain: Raising the stakes for human diversity. 1. ed. London: University Of Minnesota, 2014. Cap. 22. Kindle Edition.

BINS ELY, V. H. M. Acessibilidade Espacial: condições necessárias para o projeto de ambientes inclusivos. In: Ergonomia do ambiente construído e habitado: ambiente urbano, ambiente público, ambiente laboratorial / Organizadora Anamaria de Moraes - Rio de Janeiro: iUsEr, 2004.

BORGES, M. M.; NAVEIRO, R. M. Expressão gráfica e projetos de engenharia, arquitetura e desenho industrial: considerações acerca das formas tradicionais e recursos computacionais para a representação do projeto. Ouro Preto: Revista Escola de Minhas, 2001. Disponível em: <http://www.scielo.com.br>. Acesso em: 17 março 2017.

DISCHINGER, M.; BINS ELY, V. H. M.; PIARDI, S. M. D. G. Promovendo acessibilidade espacial nos edifícios públicos: Programa de Acessibilidade às Pessoas com Deficiência ou Mobilidade Reduzida nas Edificações de Uso Público. Florianópolis: MPSC, 2012. 161 p.

ELALI, G. A. Mais do que paredes: algumas considerações sobre aspectos subjetivos da habitação. In: Anais do II congresso Brasileiro e I lbero-americano de Habitação Social. Florianópolis, Santa Catarina, 2006. s/p.

FARIAS, F.; SANDERSON, H. S; PORTO, V. Comunicação não-verbal e libras. In: XVI Congresso Internacional de Humanidades. Anais... . Brasília: Universidade de Brasília, 2013. p. 1 - 2. Disponível em: <http://periodicos.unb.br/index.php/intercambio/article/ view/13171>. Acesso em: 12 set. 2017.

GANJU, A.; GUPTA, V.; KHOSLA, R. People's participation in housing: proposed pilot Project. 2012. Disponível em: http://www.architexturez.net/+/subject-listing/000043.shtml. Acesso em 17 nov. 2016.

HURLEY, A. K. How Gallaudet University's Architects Are Redefining Deaf Space: The world's only liberal arts institution for the Deaf creates an architectural movement. 2016. Disponível em: $<$ https://www.curbed.com/2016/3/2/11140210/gallaudet-deafspace-washington-dc>. Acesso em: 20 set. 2016.

IMAI, C.; AZUMA, M. H.; RODRIGUES R.; ZALITE M. O modelo tridimensional físico como instrumento de simulação na habitação social. Gestão e Tecnologia de Projetos, São Paulo, v. 10, n. 2, p. 7-19, jul./dez. 2015 Disponível em: <http://dx.doi.org/10.11606/gtp.v10i2.101782> Acesso em 20 nov. 2016.

IMAI, C. O processo projetual e a percepção dos usuários: $O$ uso de modelos tridimensionais físicos na elaboração de projetos na habitação social. Ambiente construído, Porto Alegre, v.9, n.2. p. 105-118, abr/jun 2009.

INSTITUTO BRASILEIRO DE GEOGRAFIA E ESTATÍSTICA (IBGE). Censo Demográfico de 2010, Brasília, 2012. Disponível em https://censo2010.ibge.gov.br/resultados.html. Acesso em janeiro/2017.

MEDEIROS, A. T. F. Projetando no Silêncio: Estratégias para participação de pessoas surdas em projetos de arquitetura residencial. Exame de Defesa (mestrado). Programa de Pós-graduação em Arquitetura e Urbanismo. Natal: UFRN, 2018.

NEUFERT, E. A arte de projetar em arquitetura: princípios, normas e prescrições sobre construção, 


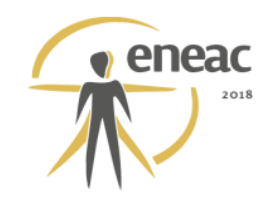

instalações, distribuição e programa de necessidades, dimensões de edifícios, locais e utensílios. São Paulo: Gustavo Gili, 1976.

PRONK, E. Dimensionamento em arquitetura. João Pessoa: Editora Universitária/UFPB, 2003

ROZESTRATEN, A. S. O desenho, a modelagem e o diálogo. Arquitextos, São Paulo, ano 07, n. 078.06, Vitruvius, nov. 2006 <http://www.vitruvius.com.br/revistas/read/arquitextos/07.078/299>. Acesso em: 17 ago. 2017.

SANOFF, H. Multiple views of participatory design. Archnet-IJAR, V.2 (1), Mar/2008, p.57-69. Disponível em: http://www.academia.edu/184343/ MultipleViewsofParticipatoryDesign. Acesso em: 3 de maio de 2016.

SANOFF, H. Special issue on participatory design. Design Studies, v. 28, n. 3, p. 213-215, 2007. Disponível em: <http://www.sciencedirect.com/science/article/pii/S0142694X07000178>. Acesso em: 18 de set de 2016.

TYSIMBAL, K. A. Deaf space and the visual world - buildings that speaks: an elementary school for the deaf. Thesis. School of Architecture Planning and Preservation. Faculty of the Graduate School of the University of Maryland, College Park, EUA, 2010.

VELOSO, M.; ELALI, G. A. Projeto como construção coletiva: da participação à colaboração - os desafios do ensino. In: III ENANPARQ: Anais do ..... São Paulo, 2014. Disponível em http://projedata.grupoprojetar.ufrn.br/dspace/ handle/123456789/2299. Acessado em outubro/2016.

ZALITE, M. G. A. A simulação com modelo físico como modo de identificação das prioridades declaradas dos usuários no projeto de habitação de interesse social. Dissertação (Mestrado em Pós-graduação em Metodologia de Projeto em AÜ), Universidade Estadual de Londrina, 2016. 